\title{
Change in Target Marker/Variant/ Mutant
}

National Cancer Institute

\section{Source}

National Cancer Institute. Change in Target Marker/Variant/ Mutant. NCI Thesaurus.

Code C139521.

Problem due to change in target marker/variant/mutant which is not covered in the labeling. 